\title{
Study of Polyolefin Gel in Organic Solvents IX. Ethylene Sequence Distribution of Ethylene-Propylene Random Copolymer and Crystalline Junction Size in Its Thermoreversible Gel $^{\dagger}$
}

\author{
Yoshihiro Moteki, Masaru OKabe, ${ }^{*}$ Masato TAKaHASHI, ${ }^{* *}$ \\ and Hideomi MATSUDA** \\ Kawasaki Plastics Laboratory, Showa Denko Co., 3-2, Chidori-cho, \\ Kawasaki-ku, Kawasaki, Kanagawa 210, Japan \\ * Department of Chemical Technology, Faculty of Engineering, \\ Kanagawa Institute of Technology, 1030, Shimo-ogino, Atsugi, \\ Kanagawa 243-02, Japan \\ ** Department of Fine Materials Engineering, Faculty of Textile \\ Science and Technology, Shinshu University, 3-15-1, Tokida, \\ Ueda, Nagano 386, Japan
}

(Received December 13, 1993)

\begin{abstract}
The crystalline junction size $\zeta$, which is the number of consecutive ethylene units per crystalline sequence such as $\left[\mathrm{CH}_{2}-\mathrm{CH}_{2}\right]_{r}$, in an ethylene-propylene (EP) copolymer gel was determined from gel-melting temperatures using the Takahashi theory. In order to examine the correlation between the size $\zeta$ and number-average length of ethylene sequences estimated from NMR measurements, an ethylene sequence distribution curve of the copolymer was established from ${ }^{13} \mathrm{C}$ NMR data assuming 1st-order Markov statistics and number-average length in number of ethylene units $\left(L_{[\mathrm{EE} \cdots \mathrm{E}]}\right)$ was calculated from its distribution curve. The average length $L_{[\mathrm{EE} \cdots \mathrm{E}]}$ determined from this curve was in good agreement with that calculated directly from $\mathrm{E} / \mathrm{P}$ triad data of NMR. Moreover, number-average length $\left(L_{[\mathrm{EE} \cdots \mathrm{E} \geqq 5]}\right)$ of ethylene sequences greater than or equal to 5 , whose value is the crystallizable minimum number of consecutive ethylene units in an EP copolymer, approximately agreed with the junction size $\zeta$ in gel, i.e., $\zeta \simeq L_{[\mathrm{EE} \cdots \mathrm{E} \geqq 5]}$.

KEY WORDS Ethylene-Propylene Random Copolymer/Thermoreversible Gel / Gel-Melting Temperature / Junction Size / ${ }^{13} \mathrm{C}$ NMR / 1st-Order Markov Statistics / Ethylene Sequence Distribution /
\end{abstract}

It is well known that an ethylene-propylene (EP) copolymer changes from crystalline to noncrystalline depending exceedingly on propylene content $(\mathrm{PC})$, sequence distribution of $\mathrm{E} / \mathrm{P}$ monomer units, and average length of ethylene sequences. If suitable numbers of propylene units are introduced randomly along polyethylene backbone chains, the copolymer shows amorphous-like properties. Because, methyl branches due to propylene units are incorporated into a crystalline lattice of polyethylene expanding the orthorhombic unit cell volume, and the lattice regularity begins to be destroyed. ${ }^{1}$ According to the results of Maurer, ${ }^{2}$ a random type of EP copolymer shows the lowest glass transition temperature $\left(T_{\mathrm{g}}\right)$ near $\mathrm{PC}=30-40 \mathrm{~mol} \%$. When $\mathrm{PC}$ is less than or greater than this range (i.e., $\mathrm{PC}<$ $30 \mathrm{~mol} \%$ or $\mathrm{PC}>40 \mathrm{~mol} \%), T_{\mathrm{g}}$ rises and the copolymer shows gradually crystalline properties.

In our previous studies ${ }^{3,4}$ of this series, EP

† Presented in part at the 42nd Annual Meeting of the Society of Polymer Science, Japan, June 1993 [Polym. Prepr. Jpn., 42, 854 (1993)] and the 42nd Polymer Symposium of the Society of Polymer Science, Japan, September 1993 [Polym. Prepr. Jpn., 42, 2631 (1993)]. 
copolymers in organic solvents (such as carbon disulfide, toluene, cyclopentane, $n$-hexane, and $n$-octane) were found to convert to thermally reversible gels when the solutions were cooled below $\mathrm{ca}$. $-40^{\circ} \mathrm{C}$. In those studies, the sizes of crystalline junctions $\zeta$ formed in the gels were estimated experimentally as a function of PC from the analysis of gel-melting temperatures using the thermodynamic theory derived by Takahashi. ${ }^{5}$ It was found that the junction sizes $\zeta \simeq 5-11$ were obtained for EP samples with $\mathrm{PC}=22-49 \mathrm{wt} \%$. As the junctions were thus very small, the reliability of $\zeta$ was not always examined definitely from X-ray diffraction measurements. Because, scattering intensity due to crystalline junctions was very weak.

In this study, a reasonable sequence distribution curve of ethylene units in an EP copolymer is estimated statistically from 1storder Markov process using ${ }^{13} \mathrm{C}$ NMR data. If such a distribution curve can be established from the statistical treatment, numberaverage length in number of consecutive ethylene units, i.e., $L_{[\mathrm{EE} \cdots \mathrm{E}]}$ in Figure 1(a), also can be calculated. As ethylene sequences $[\mathrm{EE} \cdot \mathrm{E}]$ with appropriate length along an EP chain are crystallizable units (though, for example, only one ethylene unit can not crystallize), it is suggested that there may be the correspondence between the crystallizable ethylene sequence length estimated statistically
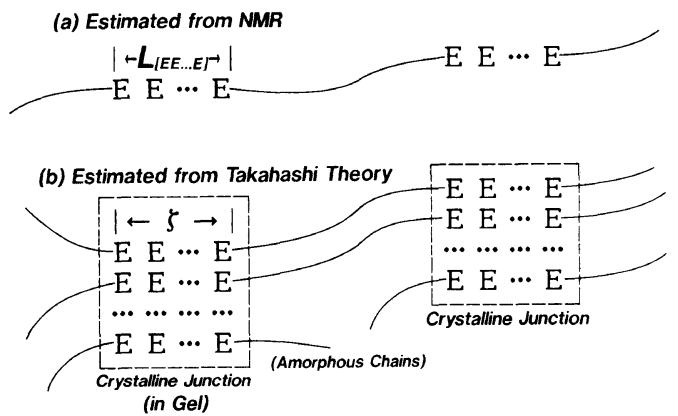

Figure 1. Number-average length in number of consecutive ethylene (E) units $L_{[\mathrm{EE} \cdots \mathrm{E}]}$ estimated from ${ }^{13} \mathrm{C}$ NMR measurements and crystalline junction size $\zeta$ in number of consecutive ethylene units estimated from the Takahashi theory. from the sequence distribution curve and the crystalline junction size $\zeta$ shown in Figure 1(b). That is, it is predicted that the crystallizable ethylene sequences along an EP chain may directly participate in forming a crystalline junction $\zeta$ in the gel. If so, the reliability of $\zeta$ also can be examined. The discussion regarding correlation between the crystallizable ethylene sequence length in the primary structure of an EP chain and the ethylene sequence length $\zeta$ in the higher structure such as a crystalline junction point has never been carried out for EP-organic solvent gels.

From the above-mentioned viewpoint, the size of crystalline junction $\zeta$ in an EP copolymer gel is estimated successively from the previous study $^{4}$ with the aid of the Takahashi theory using another solvents. Then, $\zeta$ is compared with crystallizable ethylene sequence length which can be estimated statistically from the sequence distribution curve of ethylene units.

Another purpose of this study is to investigate the thermal hysteresis between sol $\rightarrow$ gel and gel $\rightarrow$ sol transition temperatures as a function of PC from the falling-ball method. Then, the sol $\rightleftarrows$ gel transition temperatures are compared with crystallization and crystallitemelting temperatures, which can be both determined from DSC measurements.

\section{EXPERIMENTAL}

\section{Materials}

Seven samples of unfractionated EP random copolymers were used, which were all supplied by Japan Synthetic Rubber Co. Physical properties of the samples are summarized in Table I. Propylene content (PC) was determined from both IR and ${ }^{13} \mathrm{C}$ NMR measurements. For each sample, PC data obtained by IR and NMR are nearly in agreement with each other within experimental errors. All samples were dissolved completely in xylene ( $c a .3[\mathrm{wt} / \mathrm{vol} \%])$ at its boiling point under a reflux and precipitated in an excess of cooled methanol. Then, the precipitates were 
Table I. Physical properties of EP samples

\begin{tabular}{|c|c|c|c|c|c|c|c|c|}
\hline \multirow{3}{*}{ Sample } & \multirow{2}{*}{\multicolumn{2}{|c|}{ GPC data }} & \multicolumn{3}{|c|}{$\mathrm{PC}^{\mathrm{c}}$} & \multicolumn{2}{|c|}{ DSC data } & \multirow{3}{*}{$\frac{\text { NMR data }}{r_{1} r_{2}{ }^{\mathrm{f}}}$} \\
\hline & & & \multirow[b]{2}{*}{$w t \%$} & ata & NMR data & $T_{\mathrm{sd}}$ & $X^{\mathrm{e}}$ & \\
\hline & $\bar{M}_{w} \times 10^{-4 \mathrm{a}}$ & $N^{\mathbf{b}}$ & & $\mathrm{mol} \%$ & $\mathrm{~mol} \%$ & ${ }^{\circ} \mathrm{C}$ & $\%$ & \\
\hline EP-17 & 17.1 & 5781 & 22 & 16 & 17.8 & 49.1 & 5.0 & 0.35 \\
\hline EP-19 & 19.0 & 6423 & 22 & 16 & - & 48.4 & 4.6 & - \\
\hline EP-21 & 21.2 & 7167 & 22 & 16 & - & 49.3 & 5.7 & - \\
\hline EP-22 & 21.5 & 7192 & 26 & 19 & 22.1 & 47.5 & 1.3 & 0.43 \\
\hline EP-28 & 28.2 & 9399 & 27 & 20 & - & 45.8 & 1.3 & - \\
\hline EP-35 & 35.0 & 11666 & 27 & 20 & - & 44.2 & 0.6 & - \\
\hline EP-38 & 37.7 & 11713 & 49 & 39 & 35.3 & - & - & 0.75 \\
\hline
\end{tabular}

a Weight-average molecular weight determined by GPC.

b Weight-average degree of polymerization.

c Propylene content.

d Melting temperature determined by DSC.

e Degree of crystallinity estimated from DSC.

f Product of monomer reactivity ratio.

filtered and dried sufficiently under reduced pressure at $30^{\circ} \mathrm{C}$.

Methylcyclohexane $\left(\mathrm{mp}=-126.6^{\circ} \mathrm{C} ; \mathrm{bp}=\right.$ $\left.100.9^{\circ} \mathrm{C}\right)$ and $n$-heptane $\left(\mathrm{mp}=-90.7^{\circ} \mathrm{C} ; \mathrm{bp}=\right.$ $98.4^{\circ} \mathrm{C}$ ) were used as solvents for gelation. The solvents were dried with $\mathrm{CaCl}_{2}$ and then purified by distillation before use.

\section{Preparation of Gel and Measurement of Gel- Melting Temperature}

Preparation method of gel was similar to that proposed in the previous study. ${ }^{3}$ Gelmelting temperatures $\left(T_{\mathrm{m}}^{\mathrm{g}}\right)$ were measured by means of the so-called falling-ball method using a steel ball of ca. $30 \mathrm{mg}$ weight with $2 \mathrm{~mm}$ diameter. This steel ball size was similar to that used in the previous studies. ${ }^{3,4}$

\section{Differential Scanning Calorimetry (DSC)}

DSC measurements were carried out with a Shimadzu heat flux differential scanning calorimeter, Model DSC-50. Cooling and heating DSC runs were performed under a constant flow of helium gas. Liquid nitrogen was used as a coolant.

\section{${ }^{13}$ C NMR Measurement}

The ${ }^{13} \mathrm{C}$ NMR spectra were obtained using a JEOL Fourier transform NMR spectrometer, Model GSX-400, at $100.40 \mathrm{MHz}$ and $120^{\circ} \mathrm{C}$ with the broad-band noise decoupling mode. Solutions were prepared by dissolving EP copolymers in $75 \mathrm{vol} \%$ of 1,2,4-trichlorobenzene (TCB) and $25 \mathrm{vol} \%$ of $\mathrm{C}_{6} \mathrm{D}_{6}$. Experimental conditions were as follows: pulse angle, $45^{\circ}$; pulse width, $8.0 \mu \mathrm{s}$; pulse interval, $5 \mathrm{~s}$; and internal chemical shift reference, hexamethyldisiloxane (HMDS) with $2 \mathrm{ppm}$.

\section{RESULTS AND DISCUSSION}

\section{Gel-Melting Temperature vs. Polymer Con- centration}

All of semi-dilute EP solutions converted to gels on cooling, which in turn converted to sols on heating. In a dilute solution below $c a$. $1 \mathrm{~g} / 100 \mathrm{~cm}^{3}$, no gel was formed but crystalliquid phase separation occurred macroscopi- 
cally.

Relation between gel-melting temperature $\left(T_{\mathrm{m}}^{\mathrm{g}}\right)$ and polymer concentration $(C)$ in

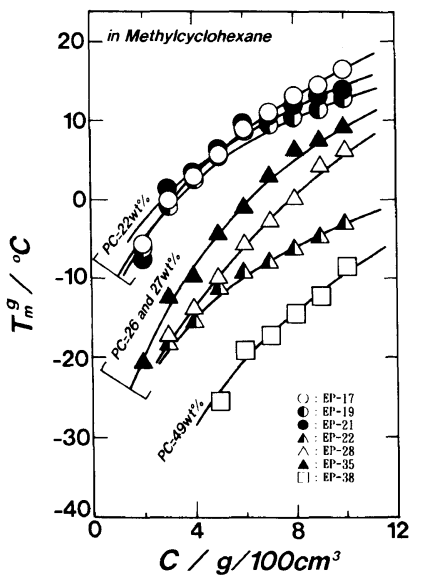

Figure 2. Relation between gel-melting temperature $T_{\mathrm{m}}^{\mathrm{g}}$ and polymer concentration $C$ in methylcyclohexane: PC, propylene content estimated from IR measurements. $O$, EP-17; $\bigcirc$, EP-19; $\bigcirc$ EP-21; $\triangle$, EP-22; $\triangle$, EP-28; $\boldsymbol{\Delta}$, EP-35; $\square$, EP-38.

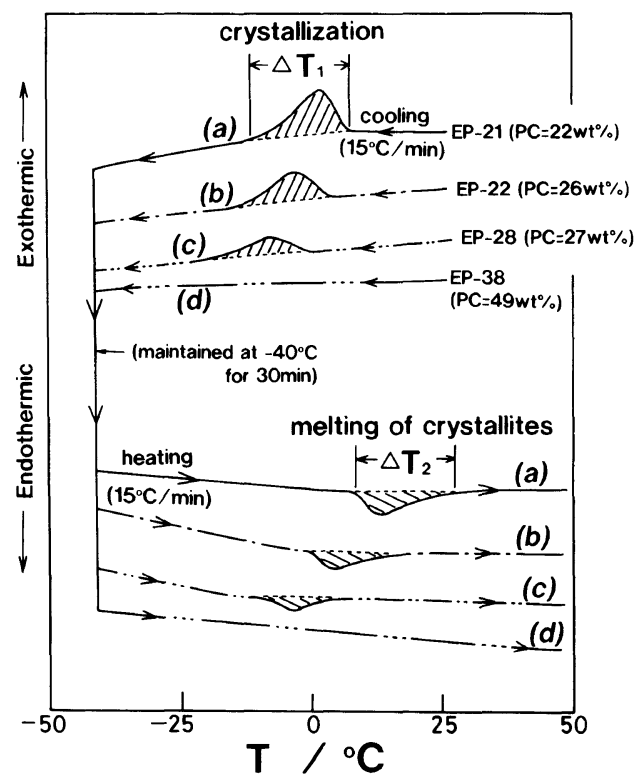

(A) methylcyclohexane, established from the falling-ball method, is shown in Figure 2. It is obvious that $T_{\mathrm{m}}^{\mathrm{g}} v s$. $C$ curves of all samples are classified broadly into three groups according to PC of samples, i.e., the highest $T_{\mathrm{m}}^{\mathrm{g}}$ group: $\mathrm{PC}=22 \mathrm{wt} \%$; the middle $T_{\mathrm{m}}^{\mathrm{g}}$ group: $\mathrm{PC}=26$ and $27 \mathrm{wt} \%$; and the lowest $T_{\mathrm{m}}^{\mathrm{g}}$ sample: $\mathrm{PC}=49 \mathrm{wt} \%$. As a whole, $T_{\mathrm{m}}^{\mathrm{g}}$ curves lower considerably with increasing PC. In other words, $T_{\mathrm{m}}^{\mathrm{g}}$ curves become higher with decreasing methyl branches due to propylene units.

\section{Relation between Sol $\rightarrow$ Gel and Gel $\rightarrow$ Sol Tran- sitions}

According to the results shown in Figure 2, $T_{\mathrm{m}}^{\mathrm{g}}$ depends seriously on PC. Therefore, an EP gel is crystalline and junction points are made up of crystallites. In order to investigate more detailedly whether gelation takes place accompanying with crystallization of polymers from solution or not, on the contrary, whether melt-

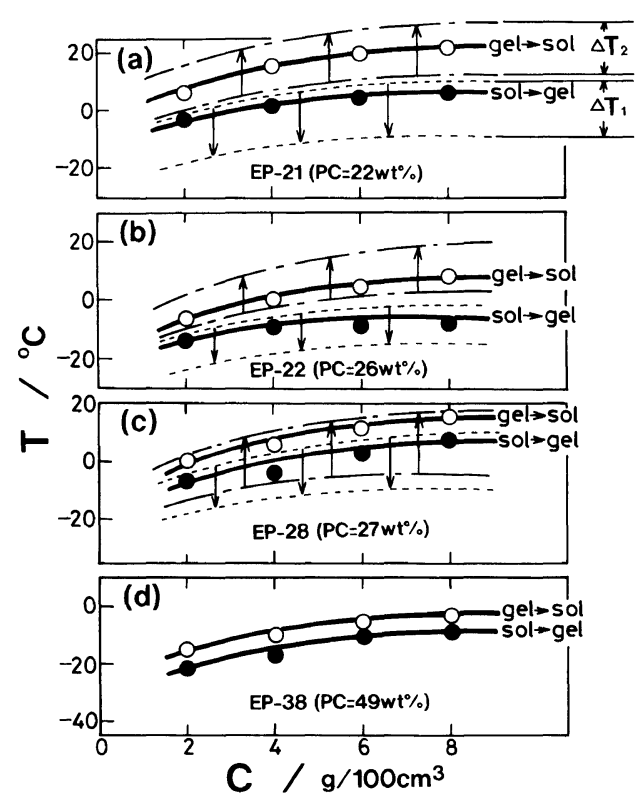

(B)

Figure 3. (A): Exothermic and endothermic peaks obtained from cooling and heating DSC measurements for EP-toluene systems with the same concentrations of $8 \mathrm{~g} / 100 \mathrm{~cm}^{3}$. (B): Sol $\rightleftarrows$ gel transition temperatures measured by the falling-ball method, exothermic peak width $\Delta T_{1}$ in a DSC curve, and endothermic peak width $\Delta T_{2}$, which were all obtained for EP-toluene systems. 
ing of gel takes place accompanying with melting of crystallites or not, cooling and heating DSC measurements were carried out. At first, the cooling DSC run was carried out for an EP solution at a cooling rate of $15^{\circ} \mathrm{Cmin}^{-1}$ from room temperature till $-40^{\circ} \mathrm{C}$, and maintained at this temperature for $30 \mathrm{~min}$. Then, the heating DSC run was carried out successively at a heating rate of $15^{\circ} \mathrm{Cmin}^{-1}$ from $-40^{\circ} \mathrm{C}$ till $70^{\circ} \mathrm{C}$.

Cooling and heating DSC patterns thus obtained are shown in Figure 3(A). Both exothermic and endothermic peaks are observed for each sample except for EP-38. The heat effect of the sample EP-38, which has the highest content of propylene units, was too small for both exothermic and endothermic peaks to be distinguished from a change in DSC base line.

The temperature region $\Delta T_{1}$ (in Figure 3(A)) for crystallization of polymers from solution and the region $\Delta T_{2}$ for melting of crystallites in a gel were compared with gelation ( $\mathrm{sol} \rightarrow$ gel transition) and gel-melting (gel $\rightarrow$ sol transition) temperatures measured by the falling-ball method. The method for determination of gelation temperature was similar to that proposed in the previous study. ${ }^{3}$ As shown in Figure 3(B), the sol $\rightarrow$ gel transition (O) takes place inside the crystallization region $\left(\Delta T_{1}\right)$ of polymers from solution. While, the gel $\rightarrow$ sol transition $(O)$ occurs inside the melting region $\left(\Delta T_{2}\right)$ of crystallites in gel. Thus, it is said definitely that the gelation occurs through crystallization and that the melting of gel occurs through melting of crystallites which are junction points of the gel network.

Further, in Figure 3(B), there is the temperature difference (i.e., thermal hysteresis) between gel $\rightarrow$ sol $(\bigcirc)$ and sol $\rightarrow$ gel (O) transitions for each sample. The hysteresis becomes gradually small with increasing PC. It is, therefore, very clear that formation and melting of crystalline junctions of a gel never take place at the same temperature in case of semicrystalline EP samples. For an amorphous atactic polystyrene gel, however, it was already reported that $\mathrm{sol} \rightleftarrows$ gel transition temperatures coincided with each other within experimental errors. ${ }^{6}$ In this sense, the decrease in temperature difference between sol $\rightleftarrows$ gel transitions with increasing PC may lead to the fact that the size of crystalline junction in an EP gel becomes small with increasing PC. In the following section, the junction sizes formed in the gels are estimated quantitatively from $T_{\mathrm{m}}^{\mathrm{g}}$ data using the Takahashi theory.

\section{Estimation of $\zeta$ from the Takahashi Theory}

Takahashi studied many kinds of thermally reversible polymer gels ${ }^{7}$ and derived the useful theory for estimating the crystalline junction size $\zeta$ of gel, where fringed micelle-type morphology was modelled for the junction as shown in Figure 4. According to our previous studies of EP gels, ${ }^{3,4}$ the junction point morphology was not a typically folded chain lamella but fringed micellar-like crystallite was most suitable for the junction morphology. Thus, the Takahashi theory is applicable to EP copolymer gels. The theory is written as follows 5 :

$$
\begin{aligned}
\frac{1}{T_{\mathrm{m}}^{\mathrm{g}}}= & \frac{\zeta}{\zeta \Delta h_{\mathrm{u}}+\zeta B^{\prime} V_{\mathrm{A}}-2 \sigma_{\mathrm{ec}}} \\
& \times\left(\frac{\Delta h_{\mathrm{u}}}{T_{\mathrm{m}}^{0}}+\frac{R V_{\mathrm{A}}}{V_{1}}-R \ln X_{\mathrm{A}}\right) \\
& -\frac{R}{\zeta \Delta h_{\mathrm{u}}+\zeta B^{\prime} V_{\mathrm{A}}-2 \sigma_{\mathrm{ec}}} \ln V_{2} N
\end{aligned}
$$

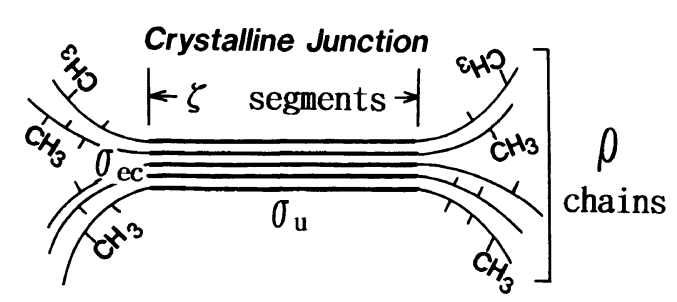

Figure 4. Crystalline junction point model proposed by Takahashi: $\zeta$, number of consecutive ethylene units per crystalline sequence in a copolymer chain; $\sigma_{\mathrm{ec}}$, end interfacial free energy; $\sigma_{\mathrm{u}}$, lateral surface free energy; $\rho$, number of copolymer chains in the junction; $-\mathrm{CH}_{3}$, methyl branch due to propylene unit. 


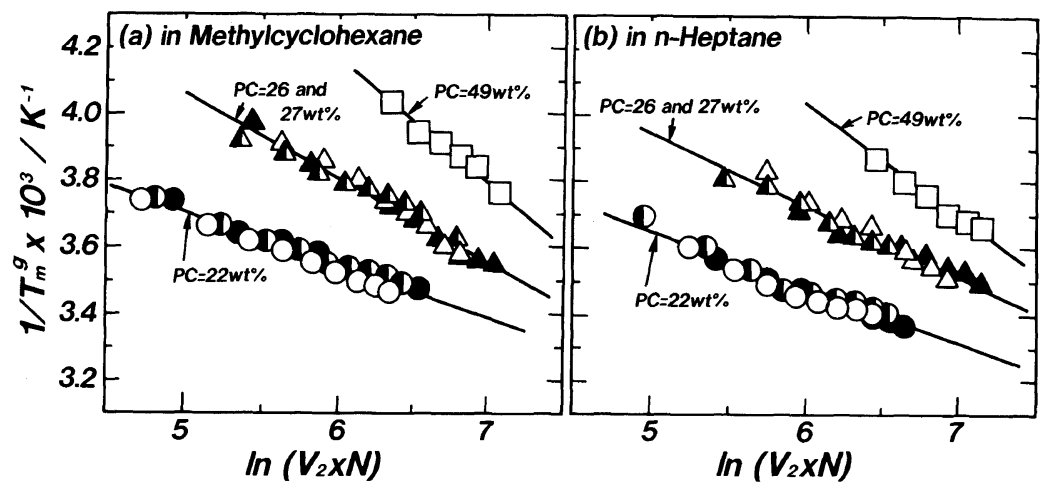

Figure 5. Plot of $1 / T_{\mathrm{m}}^{\mathrm{g}} v s$. $\ln V_{2} N$ according to eq 1: (a), obtained in methylcyclohexane; (b), obtained in $n$-heptane; PC, propylene content estimated from IR. The ordinate $\left(1 / T_{\mathrm{m}}^{\mathrm{g}}\right)$ of each graph has the same scale and symbols are the same as those in Figure 2.

where $T_{\mathrm{m}}^{\mathrm{g}}[\mathrm{K}]$ is the gel-melting temperature, $\zeta$ is the size of crystalline junction in number of ethylene units (i.e., number of repeating ethylene units such as $\left.\left[\mathrm{CH}_{2}-\mathrm{CH}_{2}\right]_{\zeta}\right), \Delta h_{\mathrm{u}}$ $\left[\mathrm{J} \mathrm{mol}^{-1}\right]$ is the heat of fusion of an ethylene unit, $B^{\prime}\left[\mathrm{J} \mathrm{cm}^{-3}\right]$ is the cohesive energy density defined by $\chi_{1}=B^{\prime} V_{1} / R T, \chi_{1}$ is the FloryHuggins interaction parameter for the polymer-solvent pair, $V_{1}$ and $V_{\mathrm{A}}\left[\mathrm{cm}^{3} \mathrm{~mol}^{-1}\right]$ are the molar volumes of the solvent and crystalline unit, respectively, $\sigma_{\mathrm{ec}}\left[\mathrm{J} \mathrm{mol}^{-1}\right]$ is the end interfacial free energy per crystalline sequence, $T_{\mathrm{m}}^{0}[\mathrm{~K}]$ is the equilibrium melting temperature of a polymer, $X_{\mathrm{A}}$ is the mole fraction of crystalline (ethylene) units, $V_{2}$ is the volume fraction of the polymer in the gel, and $N$ is the weight-average degree of polymerization of the polymer.

If the reciprocal of gel-melting temperature of EP gel in organic solvents is expressed as a logarithmic function of $V_{2} N$, eq 1 suggests that the plots of $1 / T_{\mathrm{m}}^{\mathrm{g}} v s$. $\ln V_{2} N$ should give a straight line for each sample. The plots of all samples are shown in Figures 5(a) and 5(b) for EP-methylcyclohexane and EP- $n$-heptane gels, respectively. The plots were nearly scaled on a common straight line when samples had similar PC. Thus, a line corresponding to each sample was not shown in Figures 5(a) and 5(b) except for the sample EP-38 with PC $=49 \mathrm{wt} \%$
( $\square$ ). As a whole, three straight lines are obtained in each solvent according to PC of samples, i.e., the line of $\mathrm{PC}=49 \mathrm{wt} \%$; the line of $\mathrm{PC}=26$ and $27 \mathrm{wt} \%$; and the line of $\mathrm{PC}=22 \mathrm{wt} \%$.

Equation 1 is, therefore, well applicable to the EP gels. According to the plot by eq 1, the effect of PC on $T_{\mathrm{m}}^{\mathrm{g}}$ is very clear. The experimental fact that a common linear relationship was found to hold between $1 / T_{\mathrm{m}}^{\mathrm{g}}$ and $\ln V_{2} N$ for the samples with similar PC suggests qualitatively that the sizes of crystalline junctions $\zeta$ are nearly equal to one another in the samples with similar PC.

By plotting $1 / T_{\mathrm{m}}^{\mathrm{g}}$ against $\ln V_{2} N$ for each sample, the crystalline junction size $\zeta$ was determined from the intercept and slope of each straight line according to the method described in the previous study. ${ }^{4}$ Values of $\zeta$ thus determined are summarized in Table II, together with data reported previously. ${ }^{4}$ As expected above, values of $\zeta$ show nearly the same magnitude for the samples with similar PC as shown in Table II, independently of differences in gelation solvents. That is, the following average values of $\zeta$ are obtained: $\zeta \simeq 11$ for the samples with $\mathrm{PC}=22 \mathrm{wt} \% ; \zeta \simeq 9$ for the samples with $\mathrm{PC}=26$ and $27 \mathrm{wt} \%$; and $\zeta \simeq 5$ for the sample with $P C=49 \mathrm{wt} \%$, as listed in the last column of Table II. Thus, it was 
Table II. Values of $\zeta$ estimated from the Takahashi theory

\begin{tabular}{|c|c|c|c|c|c|c|c|c|c|}
\hline \multirow[b]{2}{*}{ Sample } & \multirow{2}{*}{$\frac{\mathrm{PC}^{\mathrm{a}}}{w \mathrm{t} \%}$} & \multicolumn{8}{|c|}{$\zeta^{\mathbf{b}}$} \\
\hline & & $\mathrm{CS}_{2}$ & Toluene & Cyclopentane & $\begin{array}{c}\text { Methyl- } \\
\text { cyclohexane }^{c}\end{array}$ & $n$-Hexane & $n$-Heptane ${ }^{\mathrm{c}}$ & $n$-Octane & (Average) \\
\hline EP-17 & 22 & 12.1 & 12.1 & 10.7 & 9.6 & 9.7 & 10.9 & 9.4 & \\
\hline EP-19 & 22 & 10.4 & 11.5 & 10.1 & 12.5 & 10.7 & 9.5 & 9.4 & (11) \\
\hline EP-21 & 22 & 13.9 & 11.2 & 12.0 & 11.7 & 9.4 & 11.0 & 12.4 & \\
\hline EP-22 & 26 & 10.5 & 9.8 & 8.7 & 8.0 & 6.7 & 8.9 & 8.0 & \\
\hline EP-28 & 27 & 9.7 & 9.8 & 8.6 & 8.4 & 7.1 & 6.7 & 8.0 & (9) \\
\hline EP-35 & 27 & 9.8 & 8.9 & 8.6 & 8.7 & 7.9 & 7.0 & 8.1 & \\
\hline EP-38 & 49 & 6.3 & 6.9 & 4.8 & 5.7 & 4.6 & 6.3 & 3.7 & ( 5) \\
\hline
\end{tabular}

a Propylene content measured by IR.

b Size of crystalline junction in number of ethylene units such as $\left[\mathrm{CH}_{2}-\mathrm{CH}_{2}\right]_{\zeta}$.

c Measured in this study.

found quantitatively that the junction size $\zeta$ in number of ethylene units definitely decreased when methyl branches due to propylene units increased. In the following section, the size of crystalline junction $\zeta$ is compared with ethylene sequence length which can be estimated statistically from ${ }^{13} \mathrm{C}$ NMR data.

\section{Sequence Distribution of Ethylene Units}

It is well known that three kinds of EP copolymers can be distinguished according to the product of monomer reactivity ratio $\left(r_{1} r_{2}\right)$ : (1) $r_{1} r_{2}=1$, where the distribution of ethylene (E) and propylene (P) units is purely random (i.e., random copolymer); (2) $r_{1} r_{2}<1$, where $\mathrm{E}$ and $\mathrm{P}$ units are alternative (i.e., alternative copolymer); and (3) $r_{1} r_{2}>1$, where relatively long sequences of the same monomer unit are present (i.e., block copolymer). ${ }^{8}$ Recently, reactivity ratios for EP copolymerization with various catalyst-cocatalyst systems $\left(e . g ., \mathrm{VCl}_{4}-\right.$ $\mathrm{Al}\left(\mathrm{C}_{2} \mathrm{H}_{5}\right)_{2} \mathrm{Cl}$ [syndiospecific], $\mathrm{VCl}_{4}-\mathrm{Al}\left(\mathrm{C}_{2} \mathrm{H}_{5}\right)_{3}$ [aspecific], $\mathrm{TiCl}_{3}-\mathrm{Al}\left(\mathrm{C}_{2} \mathrm{H}_{5}\right)_{2} \mathrm{I}$ [isospecific], and so on) have been determined in order to investigate the relative monomer conversions and also the distribution of monomer sequences in an EP chain. ${ }^{8-12}$ Further, some attempts have been carried out for EP co- polymers to estimate the sequence distribution. $^{13-18}$

It is well recognized that monomer unit sequence distribution of copolymer obeys some probability statistics such as Bernoulli process or 1st- and 2nd-order Markov processes. For example, Carman et al. studied monomer unit inversions of EP copolymers with $\mathrm{PC}=20$ $60 \mathrm{wt} \%$ by identifying each structural sequence obtained from ${ }^{13} \mathrm{C}$ NMR measurements and considering all possible $\mathrm{E} / \mathrm{P}$ sequential assignments, assuming 1st-order Markovian behavior. ${ }^{14}$

On the other hand, Randall studied methylene sequence distributions and average sequence lengths in EP copolymers with $\mathrm{PC}=$ $50-60 \mathrm{wt} \%$ from a direct ${ }^{13} \mathrm{C}$ NMR quantitative method. ${ }^{15}$ Then, he determined directly a methylene sequence distribution from one to six and longer consecutive methylene carbons, $\mathrm{E} / \mathrm{P}$ ratio, and number-average sequence lengths, independently of propylene inversion or conformity to any particular statistical behavior such as the 1st-order Markov statistics. As a result, his data were similar to those reported by Carman et al. ${ }^{14}$ From this point, he proposed that the use of 1st-order Markov model in Carman's statistical 
analysis was supported for EP copolymers.

It was, therefore, found from Carman's statistical treatment that the 1st-order Markov process was well applicable to $\mathrm{E} / \mathrm{P}$ sequence distribution. So, in this study, we use the 1st-order Markov process in order to estimate ethylene sequence distributions of the present EP copolymers. The statistical treatment by Carman is, however, not always simple. In this study, more simple method is proposed and longer ethylene sequence distribution than that determined by Carman is estimated. In the purpose of this study, it is sufficient to estimate only the ethylene sequence distribution. Thus, we do not discuss the propylene sequence. The method is as follows:

We consider the reaction shown in Figure 6(a), where $P_{1}$ and $P_{2}$ are both propylene units and $E_{1}, E_{2}, \cdots, E_{n}$ are consecutive ethylene units. The function of probability density $\left(P_{\mathrm{E}}\right)_{n}$ that the chain end $E_{n}$ of EP chain reacts to $P_{2}$ can be written as follows, assuming 1st-order Markov process:

$$
\left(P_{\mathrm{E}}\right)_{n}=C_{n} \cdot P_{\mathrm{EP}}
$$

where $C_{n}$ is the constant of EP chain with arrangement $P_{1} \mathrm{E}_{1} E_{2} E_{3} \cdots E_{n}$ and $P_{\mathrm{EP}}$ is the probability that the chain end $E_{n}$ reacts to $P_{2}$. In case of the reaction shown in Figure $6(\mathrm{~b})$, the function of probability density $\left(P_{\mathrm{E}}\right)_{n+1}$ that the chain end $E_{n}$ reacts to $E_{n+1}$ and further that $E_{n+1}$ reacts to $P_{2}$ is written as

$$
\left(P_{\mathrm{E}}\right)_{n+1}=C_{n} \cdot P_{\mathrm{EE}} \cdot P_{\mathrm{EP}}
$$

where $P_{\mathrm{EE}}$ is the probability that $E_{n}$ reacts to $E_{n+1}$ and $P_{\mathrm{EP}}$ is the probability that $E_{n+1}$ reacts to $P_{2}$. Introducing eq 2 into eq 3 , we can obtain

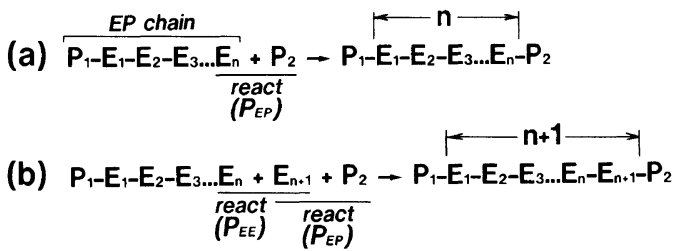

Figure 6. Reaction probabilities $P_{\mathrm{EP}}, P_{\mathrm{EE}}$, and $P_{\mathrm{EP}}$ according to 1st-order Markov process. the equation

$$
\left(P_{\mathrm{E}}\right)_{n+1}=\left(P_{\mathrm{E}}\right)_{n} \cdot P_{\mathrm{EE}}
$$

Equation 4 is the so-called geometric sequence, thus the general term is written as

$$
\left(P_{\mathrm{E}}\right)_{n}=A \cdot\left(P_{\mathrm{EE}}\right)^{n-1}
$$

where $A$ is the first term of the geometric series. As the sum of the left-hand side of eq 5 is equal to unity (i.e., $\left.\sum_{n=1}^{\infty}\left(P_{\mathrm{E}}\right)_{n}=1\right)$, the following equation is derived for a polymer chain with infinite molecular weight:

$$
\sum_{n=1}^{\infty} A \cdot\left(P_{\mathrm{EE}}\right)^{n-1}=A /\left(1-P_{\mathrm{EE}}\right)=1
$$

Thus, the first term $A$ is given as

$$
A=1-P_{\mathrm{EE}}=P_{\mathrm{EP}}
$$

Introducing eq 7 into eq 5 , we obtain finally the following equation for the function of probability density $\left(P_{\mathrm{E}}\right)_{n}$ :

$$
\left(P_{\mathrm{E}}\right)_{n}=\left(1-P_{\mathrm{EE}}\right) \cdot\left(P_{\mathrm{EE}}\right)^{n-1}=P_{\mathrm{EP}} \cdot\left(P_{\mathrm{EE}}\right)^{n-1}
$$

where $n$ is the number of consecutive ethylene units. Therefore, if we have the data of reactivity probabilities $P_{\mathrm{EP}}$ and $P_{\mathrm{EE}}$, the probability distribution $\left(P_{\mathrm{E}}\right)_{n}$ can be determined from eq 8.

On the other hand, number-average length in number of ethylene units $L_{[\mathrm{EE} \cdots \mathrm{E}]}$ is determined from a sum of expectation of the probability distribution $\left(P_{\mathrm{E}}\right)_{n}$ in eq 8 as follows:

$$
L_{[\mathrm{EE} \cdots \mathrm{E}]}=\left(\overline{P_{\mathrm{E}}}\right)_{n}=\sum_{n=1}^{\infty}\left[n \cdot\left(P_{\mathrm{E}}\right)_{n}\right]=1 / P_{\mathrm{EP}}
$$

Thus, a numerical value of $P_{E P}$ is known, the number-average length $L_{\text {[EE } \cdots \mathrm{E}]}$ of consecutive ethylene units is calculated directly from eq 9.

Values of reactivity probabilities $P_{\mathrm{EP}}, P_{\mathrm{PE}}$, and $P_{\text {EE }}$ are summarized in Table III, which were determined from NMR data assuming 1st-order Markov process. In the same table, furthermore, triad sequence distributions are listed. Introducing the numerical values of $P_{\mathrm{EP}}$ and $P_{\mathrm{EE}}$ into eq 8 , the probability density $\left(P_{\mathrm{E}}\right)_{n}$ was calculated as a function of $n$. 
Table III. Probabilities according to 1st-order Markov process and triad sequence distributions estimated from ${ }^{13} \mathrm{C}$ NMR

\begin{tabular}{|c|c|c|c|c|c|c|c|c|c|}
\hline \multirow{2}{*}{ Sample } & \multicolumn{3}{|c|}{ Probability } & \multicolumn{6}{|c|}{ Triad in $\mathrm{mol} \%$} \\
\hline & $P_{\mathrm{EP}}^{\mathrm{a}}$ & $P_{\mathrm{PE}}^{\mathrm{b}}$ & $P_{\mathrm{EE}}^{\mathrm{c}}$ & [EEE] & [EEP] & [EPE $]$ & {$[\mathrm{PEP}]$} & {$[\mathrm{PPE}]$} & [PPP] \\
\hline EP-17 & 0.201 & 0.926 & 0.799 & 52.9 & 28.3 & 13.8 & 2.6 & 2.4 & 0.0 \\
\hline EP-22 & 0.252 & 0.888 & 0.748 & 44.7 & 32.3 & 15.7 & 4.2 & 2.8 & 0.3 \\
\hline EP-38 & 0.380 & 0.700 & 0.620 & 24.7 & 33.7 & 16.1 & 9.7 & 10.9 & 4.9 \\
\hline
\end{tabular}

${ }^{\text {a }}$ Probability that chain end E (ethylene) reacts to $\mathrm{P}$ (propylene).

b Probability that chain end $P$ reacts to $E$.

c Probability that chain end $\mathrm{E}$ reacts to $\mathrm{E}$, which is equal to $1-P_{\mathrm{EP}}$.

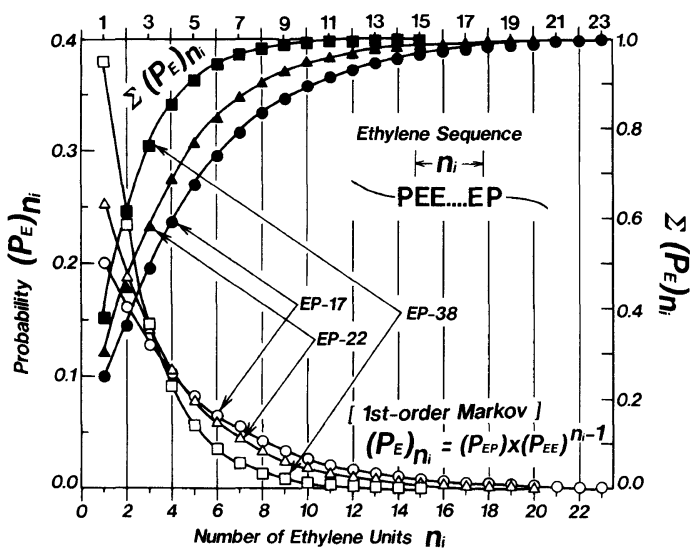

Figure 7. Probability distribution of ethylene sequence length established from eq $8: \sum\left(P_{\mathrm{E}}\right)_{n_{i}}$, integral distribution curve of eq $8 ;\left(P_{\mathrm{E}}\right)_{n_{i}}$, normalized probability distribution function of ethylene sequence length.

Ethylene sequence distribution curves $\left(P_{\mathrm{E}}\right)_{n_{i}}$ obtained for three samples EP-17, EP-22, and EP-38 are shown in Figure 7, where integral distribution curves $\sum\left(P_{\mathrm{E}}\right)_{n_{i}}$ (symbols: $\mathbf{0}, \boldsymbol{\Lambda}$, and $\square$ ) are also illustrated. Figure 8 is the semilogarithmic plot of Figure 7. Three straight lines with different slopes are obtained as shown in Figure 8 for the samples EP-17, EP-22, and EP-38, whose propylene contents are different from one another. The line of EP-38, which contains much propylene units randomly, has a steep slope of all samples. This means that the sample EP-38 has few numbers of consecutive long ethylene sequences in comparison with the samples EP-17 and EP-22.

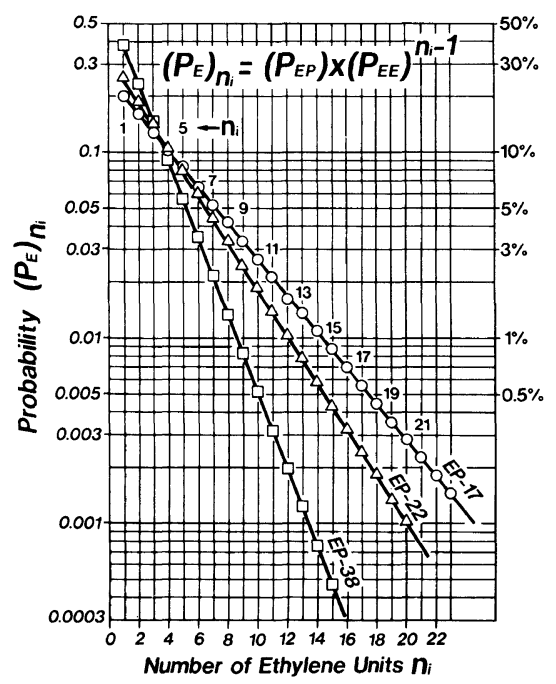

Figure 8. Semilogarithmic plot of $\left(P_{\mathrm{E}}\right)_{n_{i}} v s . n_{i}$ according to eq 8 .

Number-average lengths in number of ethylene units $L_{[\mathbf{E E} \cdots \mathbf{E}]}$ were determined for three samples from their distribution curves shown in Figure 7 using the following equation:

$$
L_{\mathrm{IEE} \cdots \mathrm{E}]}=\sum_{n_{i}=1}^{\infty} n_{i} \cdot\left(P_{\mathrm{E}}\right)_{n_{i}}
$$

The values obtained from eq 10 are summarized in Table IV. In this table, values of $L_{\text {[EE } \cdots \mathrm{E}]}$ calculated directly from eq 9 using the data $P_{\text {EP }}$ shown in Table III and those determined from triad data in Table III using the equation ${ }^{19}$ 
Table IV. Number-average length of consecutive ethylene units and crystalline junction size

\begin{tabular}{ccccccc}
\hline & \multicolumn{3}{c}{$L_{[\mathrm{EE} \cdots \mathrm{E}]}^{\mathrm{a}}$} & & $L_{[\mathrm{EE} \cdots \mathrm{E} \geqq 5]}^{\mathrm{b}}$ & $\zeta^{\mathrm{c}}$ \\
\cline { 2 - 3 } & From eq 9 & $\begin{array}{c}\text { From distribution } \\
(\text { eq 10) }\end{array}$ & From eq 11 & & $\begin{array}{c}\text { From distribution } \\
(\text { eq 12) }\end{array}$ & $\begin{array}{c}\text { From Takahashi } \\
\text { theory (eq 1) }\end{array}$ \\
\hline EP-17 & $4.9_{7}$ & $4.9_{7}$ & $5.0_{0}$ & & $8.9_{4}$ & 11 \\
EP-22 & $3.9_{6}$ & $3.9_{6}$ & $3.9_{9}$ & & $7.8_{0}$ & 9 \\
EP-38 & $2.6_{3}$ & $2.6_{3}$ & $2.5_{6}$ & $6.6_{2}$ & 5 \\
\hline
\end{tabular}

a Number-average length in number of ethylene units from $E=1$ to $\infty$.

b Number-average length in number of ethylene units from $E=5$ to $\infty$.

c Junction size in number of ethylene units in gel (see Table II).

$$
L_{[\mathrm{EE} \cdots \mathrm{E}]}=\frac{[\mathrm{EEE}]+[\mathrm{EEP}]+[\mathrm{PEP}]}{[\mathrm{PEP}]+[\mathrm{EEP}] / 2}
$$

are also listed. Values of $L_{[\mathrm{EE} \cdots \mathrm{E}]}$ determined from eq 9-11 are in good agreement with one another for each sample as shown in Table IV. Thus, the ethylene sequence distribution curves established in this study and the values of $L_{\text {[EE } \cdots \mathrm{E}]}$ are considered to be reasonable.

Number-average length $L_{[\mathrm{EE} \cdots \mathrm{E}]}$ of consecutive ethylene units with $n_{i}=1 \sim \infty$ can not be compared directly with crystalline junction size $\zeta$ determined experimentally from the Takahashi theory, for relatively short ethylene sequence length such as, for example, only one ethylene unit (i.e., $n_{i}=1$ ) may not crystallize. It is known that minimum crystallizable sequence length of polyethylene, which was estimated from crystallinity by X-ray, is $c a .13$ monomer units in a solid state. ${ }^{20}$ On the other hand, according to a recent study of ethylenepropylene copolymers, the minimum sequence length that can crystallize in a solid state is $c a$. 5 ethylene units (i.e., $n_{i}=5$ ) near ambient temperature in a copolymer including $c a$. $60 \mathrm{wt} \%$ ethylene. ${ }^{21}$ This means that consecutive ethylene units with $n_{i} \geqq 5$ in an EP copolymer chain participate in crystallization in a solid state.

Crystalline junctions are formed in a gel including a solvent. Therefore, the minimum ethylene sequence length which can crystallize in a gel (or solvent) may be different from that in a solid state. There are, however, no data regarding crystallite size of polymer in a gel. So, by way of trial, we determine the number-average length of ethylene sequences with $n_{i} \geqq 5$ (i.e., $L_{[\mathrm{EE} \cdots \mathrm{E} \geqq 5]}$ ) from a distribution curve shown in Figure 7 using the following equation on the assumption that crystallizable minimum sequence length of ethylene units in a gel is same as that in a solid state:

$$
L_{[\mathrm{EE} \cdots \mathrm{E} \geqq 5]}=\sum_{n_{i}=5}^{\infty} n_{i} \cdot\left(P_{\mathrm{E}}\right)_{n_{i}} / \sum_{n_{i}=5}^{\infty}\left(P_{\mathrm{E}}\right)_{n_{i}}
$$

And, the crystalline junction size $\zeta$ formed in a gel is compared with the length $L_{[\mathrm{EE} \cdots \mathrm{E} \geqq 5]}$. Values of $L_{[\mathrm{EE} \cdots \mathrm{E} \geqq 5]}$ thus determined are listed in Table IV, together with the values of crystalline junction sizes $\zeta$. It is found that each value of $\zeta$ agrees approximately with the ethylene length $L_{[\mathrm{EE} \cdots \mathrm{E} \geqq 5]}$ estimated from NMR data.

\section{CONCLUSIONS}

The present study clarifies the following results for correlation between number-average length of ethylene sequences of EP copolymer and the size of crystalline junction formed in its copolymer gel:

1. An ethylene sequence distribution curve of EP copolymer is well established from ${ }^{13} \mathrm{C}$ NMR data assuming 1st-order Markov statistics and number-average length in number of ethylene units (i.e., $L_{[\mathrm{EE} \cdots \mathrm{E}]}$ ) can be determined 
precisely from its distribution curve.

2. Number-average length of ethylene sequences with $\mathrm{EE} \cdots \mathrm{E} \geqq 5$ (i.e., $L_{[\mathrm{EE} \cdots \mathrm{E} \geqq 5]}$ ), which can be calculated from the ethylene sequence distribution curve, is nearly in accordance with the crystalline junction size $\zeta$ in a gel. In other words, ethylene sequences with length $L_{[\mathrm{EE} \cdots \mathrm{E} \geqq 5]}$ may directly participate in forming a crystalline junction.

3. The crystalline junction size $\zeta$ decreases with decreasing number-average length of consecutive ethylene units $\left(L_{[\mathrm{EE} \cdots \mathrm{E}]}\right)$ of the copolymer and decreases with increasing propylene content (PC).

Acknowledgments. The authors express their sincere appreciation to Professor Akira Takahashi of Mie University for his suggestion in treatment of his theory. Thanks are also due to Dr. Shigeki Saito of the Ohita Research Laboratory, Showa Denko Co. for ${ }^{13} \mathrm{C}$ NMR measurements and for his useful discussion.

\section{REFERENCES AND NOTES}

1. P. R. Swan, J. Polym. Sci., 56, 409 (1962).

2. J. J. Maurer, Rubber Chem. Technol., 38, 979 (1965).

3. M. Okabe, K. Mitsui, H. Uranaka, M. Takahashi, and H. Matsuda, Polym. J., 24, 653 (1992).

4. M. Okabe, Y. Moteki, H. Uranaka, M. Takahashi, and H. Matsuda, Polym. J., 25, 955 (1993).

5. A. Takahashi, T. Nakamura, and I. Kagawa, Polym. J., 3, 207 (1972).
6. H.-M. Tan, A. Moet, A. Hiltner, and E. Baer, Macromolecules, 16, 28 (1983).

7. For example, A. Takahashi and T. Kato, Res. Rep. Fac. Eng. Mie Univ., 1, 97 (1976). In this reference, theoretical background of the Takahashi theory and many kinds of polymer gels used for estimating the size of crystalline junction from the theory are summarized.

8. Th. A. Veerkamp and A. Veermans, Makromol. Chem., 58, 147 (1961).

9. J. F. Jackson, J. Polym. Sci., A, 1, 2119 (1963).

10. C. Cozewith and G. V. Strate, Macromolecules, 4, 482 (1971).

11. C. Tosi, A. Valvassori, and F. Ciampelli, Eur. Polym. J., 5, 575 (1969).

12. G. V. Strate and Z. W. Wilchinsky, J. Polym. Sci., A-2, 9, 127 (1971).

13. A. Zambelli, G. Gatti, C. Sacchi, W. O. Crain, Jr., and J. D. Roberts, Macromolecules, 4, 475 (1971).

14. C. J. Carman, R. A. Harrington, and C. E. Wilkes, Macromolecules, 10, 536 (1977).

15. J. C. Randall, Macromolecules, 11, 33 (1978).

16. H. N. Cheng, Macromolecules, 17, 1950 (1984).

17. W. V. Smith, J. Polym. Sci., Polym. Phys. Ed., 18, 1573 (1980).

18. H. N. Cheng, J. Appl. Polym. Sci., 35, 1639 (1988).

19. K. Ito and Y. Yamashita, J. Polym. Sci., A, 3, 2165 (1965).

20. For example, R. L. Miller, "Crystallinity," in "Encyclopedia of Polymer Science and Technology," Vol. 4, H. F. Mark, N. G. Gaylord, and N. M. Bikales, Ed., Wiley-Interscience, New York, N.Y., 1966, p 449.

21. For example, G. V. Strate, "Ethylene-Propylene Elastomers," in "Encyclopedia of Polymer Science and Engineering," Vol. 6, 2nd ed, H. F. Mark, N. M. Bikales, C. G. Overberger, G. Menges, and J. I. Kroschwitz, Ed., Wiley-Interscience, New York, N.Y., 1986, p 522. 